\title{
Knowledge Management System Approach for Student's Appeal Domain: A Study
}

\author{
Mary Ann C. Paguio, PhD \\ HCT-IT, Muscat, Oman
}

\author{
Shaniba Fasal \\ HCT-IT, Muscat Oman
}

\author{
Dennis B. Gonzales, PhD \\ University of the East, \\ Philippines
}

\begin{abstract}
Knowledge Management is a term used as a systematic and organizationally specified process for acquiring, organizing, and communicating both tacit and explicit knowledge of employees so that other employees may make use of it to be more effective and productive in their work." (Barnes, 2002). The study is concerned to the process of discovery, creation, dissemination and utilization of knowledge in student's appeal domain through the development of KM Portal for Student's appeal domain. KMS is a term used to address any kind of IT system that uses, stores, retrieve and disseminates the information within organization to improve the existing process that requires the tacit and explicit knowledge to be store in a fashionable way (James Robertson, 2007). The study answered the following questions: 1.) What is the KM Model appropriate in the proposed KM Portal? 2) How do the respondents evaluate the proposed KM Portal in terms of Functionality, Reliability, Usability, Efficiency, Maintainability and Portability? 3.) What software methodology model used in the development of KM Portal? The researchers used Case Study Approach in data gathering and Descriptive Research Methodology in evaluating the KM Portal. Convenience sampling was used in data collection. The output of the research is an application of KMS approach in student's appeal domain that will help the college to discover, capture and utilize the knowledge and turn into intellectual assets of the organization.
\end{abstract}

\section{General Terms}

$\mathrm{KM}$ - Knowledge Management. It is a term used to describe as the process of identifying needs and demands with activities such as discovering of a new knowledge, capturing, disseminating both tacit and explicit knowledge.

KMS - refers to the use of an IT with KM integration.

Student's Appeal - is a formal request sent by student's asking the revision on decision relating to their grades, appeal to retake the exam, take the exam when they are absent during semester examination and appeal to re-evaluate the marks or grades that they obtained.

KM Portal - is a develop system that entails with the KM integration.

\section{Keywords}

Knowledge Management Knowledge Management System, Knowledge Management Support System, KM Portal.

\section{INTRODUCTION}

Knowledge Management (KM) is not a technology thing neither a computer thing. Based on the theory of Barnes, "Knowledge Management is a term to a systematic and organizationally specified process for acquiring, organizing, and communicating both tacit and explicit knowledge of employees so that other employees may make use of it to be more effective and productive in their work." (Barnes, 2002). It is merely concerned with the entire process of discovery, creation, dissemination, and utilization of knowledge. In academic community particularly in appeal domain, it becomes a new learning branch which has been impacted by unique growth of knowledge versus information. Merging of information system and KM process is now called as Knowledge Management System. KMS is a term used to address any kind of IT system that uses, stores, retrieve and disseminates the information within organization to improve the existing process that requires the tacit and explicit knowledge to be store in a fashionable way (James Robertson, 2007).

Moreover, the main objective of the study is to develop the KM Portal for Student's Appeal domain using Knowledge Management System approach that will helps the college to estimate or projected the total number of students who will apply on each types of appeal, monitoring of graduating students who are moving to the next level, projected for opening next semester subjects from datasets of failing students and preparing the different sets of questionnaires ahead of time. The three types of appeal covered in this study are: 1.) Re-sit Exam - the students are allowed to re-take the exam. 2.) Appeal on Result of the Final Exam - the students has the right to appeal on the result of her/his final grade on their enrolled courses in the previous semester. 3.) Makeup Exam - the students can make-up the exam if he/she is absent during the time of examination.

\section{LITERATURE REVIEW}

In order to share information easily and participate in knowledge sharing, the following are the contents of KMSS(Knowledge Management Support System). (Ginsburg \& Kambil, 2002).

\section{Data or Knowledge Warehouse}

According to Rouse (2006), data from various online transaction processing are selectively extracted and organized on the data warehouse database for use by analytical applications and user queries. In the KM Portal, it will act as repository of information from various sources accessed by different users and store it in locally known as database. It has a feature of storing the knowledge or decision coming from different inputs of stakeholders.

2. Knowledge Search and Discovery Mechanisms In this area, the researchers will design the search engine for the projection of student's appeal by its specialization, level and subject.

\section{Knowledge representation via an ontology}

Knowledge representation is the same with the human reasoning but in accordance in designing of computer system that provides reasons in any 
machine-interpretable representation. Ontology defined by Grimm,et.al.(2007), as a formal explicit specification of a shared conceptualization of a domain of interest and definitions conducted as in the form of questions of "what is being? and what kind of things are there? It defines as neither explicitly stated nor logically follows from what is stated or can by no means be processed within the machine, although it might be obvious to a human. [Grimm,et.al.(2007)]. To capture the characteristics of ontology, the term "explicit", is been used as a form of knowledge representation. Apparently, the proposed KMS for Student's Appeal domain will be addressing the explicit ontology that describes the structured decisions done by Head of the Department (HoD) by capturing precise knowledge of appeal from re-sit examinations, make-up examination and appeal on final result on final grades.

\section{Knowledge quality control}

According to Firestone (2002), "software for supporting communities of practice can support knowledge production about quality". The development of software in student's appeal domain using KMS approach established quality control for knowledge for entries in the database such as filling-up the reason of the appeal by students with the corresponding decision. An academic appeal varies on different criteria depends on the grounds or reasons of student's appeal to maintained the quality of control such as the list of records and documentation, including course details, student's final grades, student's coursework and examination grades (marks breakdown), student's final examination, final examination answer script of the best students (for reference purposes) and the marking scheme for the final examination paper.

\section{Knowledge visualization techniques.}

The authors Burkhard \& Meier(2004), says that the use of visual representations to transfer knowledge is by computer and non-computer-based visualization methods formats such as sketches, diagrams, images and objects. In order to display the knowledge transfer the researchers will use a graphical representation through graphs based or chart. In this area, the system will validate the inputs from the appeal filed by the students, and it easily demonstrates the total number of students who apply the appeal.

In the study of Hecht et al.(2011), KMS has three stages of IT solutions to become successful in implementing KM and these are: adoption, acceptance and assimilation. On Figure 1, it stated that in order to have a successful KMS implementation in any firm or organization, it must have three stages model to implement, and these are: design, development and distribution. It shows the single model that intends to cover the three factors with structured guidance in order to improve adoption, acceptance and assimilation. (Hecht et. al. 2011).

Adoption - It is a term used as an IT Solutions or KMS Solution in terms of making managerial decisions. (Rogers 1995). According to Frost, this stage is influenced by design such as: innovation characteristics fit, expected results and communication characteristics. In addition, the things that does not influence are: environment, technological infrastructure, resources, and organizational characteristics. (Frost, 2010).

According to Hecht (2011), to promote KMS adoption, below are the steps:

- Start with an internal analysis of the firm.

- Evaluate information/knowledge needs \& flows, lines of communication, communities of practice, etc. These findings should form the basis of determining the systems needed to complement them.

- Make a thorough cost-benefit analysis, considering factors like size of firm, number of users, complexity of the system structure, frequency of use, upkeep \& updating costs, security issues, training costs (including ensuring acceptance) etc. improvements in performance, lower response time, lower costs (relative to the previous systems) etc.

- Evaluate existing work practices and determine how the systems will improve - and not hinder - the status quo.

- One very interesting rule of thumb presented by Botha et al (2008), is that "the more tacit the knowledge, the less high-tech the required solution". For example, expert knowledge is often best supported by multimedia communication technology and by expert finders. Beyond that, it is about human interaction and collaboration. (Hecht et. al. 2011)

Acceptance - It refers to the decision of the user to use an IT Solution or KMS Solution in any firm or organizations (Dillon \& Morris 1996). Hecht et. al. (2011), enumerated the KMS acceptance are: anxiety, ease of use, intrinsic motivation, job-fit, results demonstrability, and social factors. Promoting acceptance can be improved by:

- Involve the users in the design and implementation process when possible (Liebowitz 1999).

- Involve the user in the evaluation of the system when applicable (Liebowitz 1999).

- Make it as user friendly and as intuitive as possible (Frank 2002).

- Support multiple perspectives of the stored knowledge (Frank 2002).

- Provide adequate technical and managerial support.

- Use product champions to promote the new systems throughout the organization. (Frost, 2010).

Assimilation - In this stage, it shows the business activities or every day event of an organization and dissemination of IT solution or KMS solution towards the needs of a firm or organization. (Chatterjee et al. 2008) Hecht et. al. (2011), detailed the list of KMS assimilation as knowledge barrier, management championship, process cost, process quality, and promotion of collaboration. Assimilation can be improved by:

- Content management (Gamble \& Blackwell, 2011): In order for the system to remain useful, its content must be kept relevant through updating, revising, filtering, organization, etc.

- Perceived attractiveness factors (Gamble \& Blackwell, 2001): This includes not only the advantages of using the KMS, but also of management's ability to convince users of these advantages. 
- Proper budgeting: i.e. planning expenses and implementing a KMS that is cost efficient.

- Focus on collaboration. In particular, consider the adoption of enterprise 2.0 / KM 2.0 systems, which by design promote collaboration while generally being inexpensive and often quite popular.

- Management involvement: The system must be championed by management at all levels. (Frost, 2010)

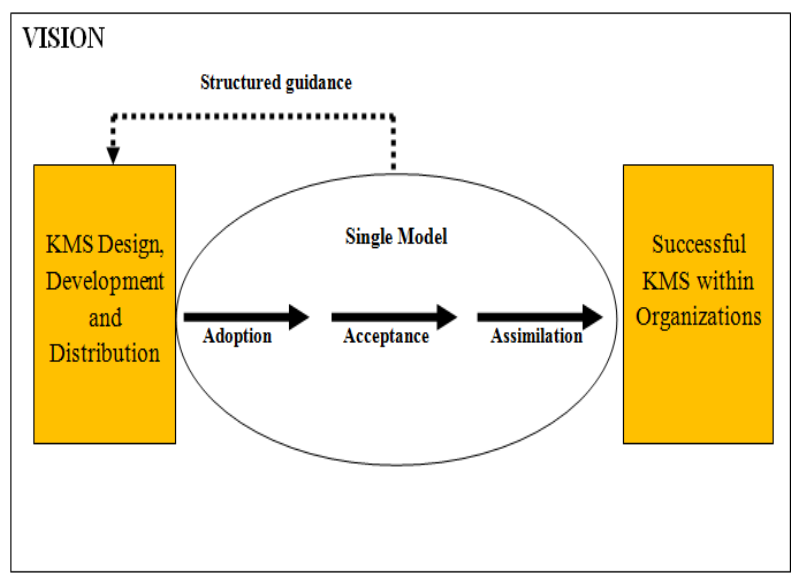

Figure 1 - Vision of KMS ( Hecht et, al, 2011)

Moreover, the context of Knowledge Management System is not only limited to the context on how to implement successfully but rather the involvement of organization in learning activities of KMS. In KMS, it has a lot of information that turns to knowledge from knowledge repositories and generating of new knowledge among communities of practice $(\mathrm{CoP})$ in collaborative environment that shows in the technical perspective proposed by Meso and Smith, 2000. Figure 2, below shows the three components of technology perspective and these are: technology, function and knowledge that includes the process of acquiring or collecting, organizing, disseminating or sharing knowledge among people in an institution. (Rusli 2005).

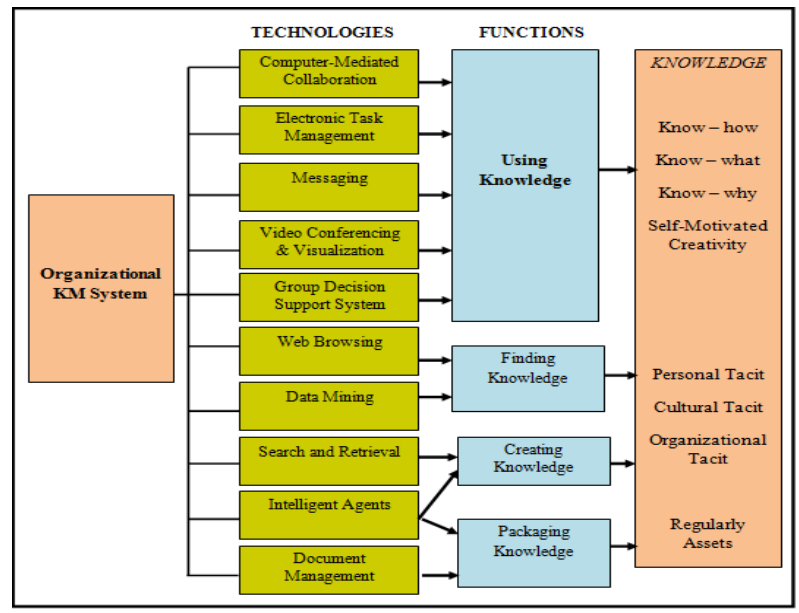

Figure 2 - Technical Perspective of a KMS ( Meso \& Smith, 2011)

\section{STATEMENT OF THE PROBLEM}

This study would like to develop a KM Portal for student's appeal domain with the integration Knowledge Management System approach. Specifically, the researchers formulate the following problems:

1. What is the KM Model appropriate in the proposed KM Portal?

2. How do the respondents evaluate the proposed KM Portal in terms of Functionality, Reliability, Usability, Efficiency, Maintainability and Portability?

3. What software methodology model used in the development of KM Portal?

\section{THEORETICAL AND CONCEPTUAL FRAMEWORK OF THE STUDY}

\subsection{Theoretical Framework}

As indicated by Frost, figure 3, demonstrates the KM Model by Botha that endeavors to offer a more practical outline of $\mathrm{KM}$ exercises. As should be obvious on the figure, every class is covered to each other and spotlights on key side of an association. The model shows generally more on individuals situated and innovation concentrate rather on authoritative and social test. (Frost,A. 2010). In this study, the utilization of KM Solutions as to add to the KM gateway for student's appeal domain can be tended the needs and demands of academic appeal domain in any HEI.

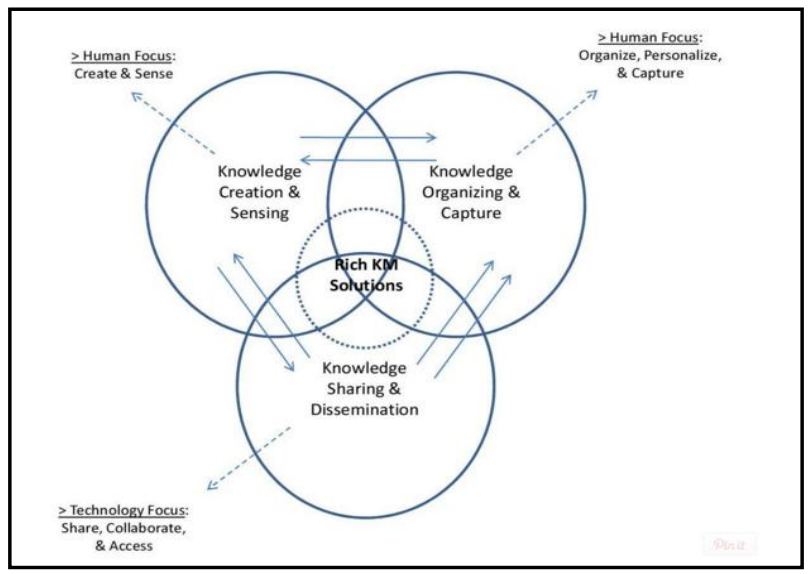

Figure 3 - KM Model by Botha (Botha et. al. 2008)

\subsection{Conceptual Framework}

The Figure 4 - conceptual framework shows the three stages of data: input, process and output. Input - It represents the data as input to the system that includes: student information, student transcript, and types of appeal, schedule, exam questionnaires and breakdown marks. This data represent different dataset in the system. Process - It pertains to the research activities in order to finish the study such as KM activities - identifying needs and demands, data collection and preparation, through the use of KM Model by Botha. It includes also the process such as: system design, development and system testing and evaluation. Output - From the processing of needed data, the KMS output is the software that will be going to developed. The long-term outcomes that the software will provide are: improved appeal process and improves decision-making for decision-maker. It includes projection, e-mail notification, audit trail and reports. It will have the feedback that goes to input to replenish the things happened on each processing. The sample reports that the 
system generates are the following: Total List of Projected/Predicted Students who will file the Re-sit, Appeal Against Final Result and Make-Up Appeal, List of Projected/Predicted Course (Subject) that the Student who will file an Appeal - Re-sit, Make-Up and Against Exam Result, List of Students who attended on Re-Sit \& Make-Up Exam, List of Passed Student in the Re-Sit \& Make-Up Exam, List of Failed Student in the Re-Sit \& Make-Up Exam, Total List of Students who applies in Re-Sit Appeal, Make-Up Appeal and Results Appeal Final Exam.

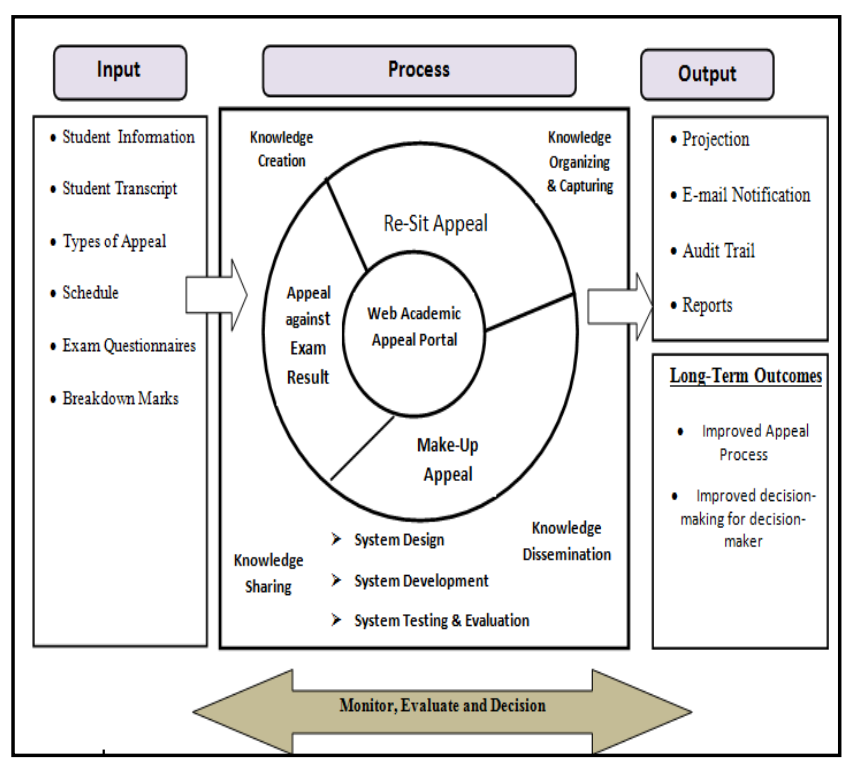

Figure 4 - Conceptual Framework

\section{MATERIALS AND METHODS}

The study used descriptive research approach to understand fully the existing process and how the software is accomplished. The drive of using the descriptive research approach is to obtain accurate, factual, and systematic data that can deliver with an actual picture of the data set that are studying.

\subsection{Research Design}

The study used descriptive research approach to understand fully the existing process and how the software is accomplished. It describes data and characteristics used to describe the population. The drive of using the descriptive research approach is to obtain accurate, factual, and systematic data that can deliver with an actual picture of the data set that are studying. Descriptive Research Method refers to the study of depicting the participants in an accurate way. The descriptive survey research will be used to explore, understand, and document the current status of the student's appeal from the Appeal Committee who will take part in this study. The researchers used 2 ways in doing descriptive research method, and these are:

A. Case Research Study, it defines as "an empirical inquiry that investigates a contemporary phenomenon within its real-life context; when the boundaries between phenomenon and context are not clearly evident; and in which multiple sources of evidence are used" (Yin, 2008). The researchers use the case study research method because it really deals with real situation to explore more in-depth methods in answering exploratory questions of Student's Appeal Committee. The following are six steps of conducting case study research: 1.) Determine and define the research questions, 2.) Select the cases and determine data gathering and analysis techniques, 3.) Prepare to collect the data, 4.) Collect data in the field, 5.) Evaluate and analyze the data and 6.) Prepare the report.

Step 1. Determine and Define the Research Questions. The first step in case study research is to establish firm research focus that deals the results from questionnaire, interview, observation, and document review findings. The researchers needs to establish the focus of the study by forming research questions about the situation or problem in terms of: current problems encountered in their manual system that will help to improve the student's appeal services, investigate and assess existing practices and policies appeal committee for knowledge preservation that serve as intellectual assets.

Step 2. Select the Cases and Determine Data Gathering and Analysis Techniques. During the design phase of case study research, the researchers determine what approaches will use in examining in-depth data gathering tool.

Step 3. Prepare to Collect the Data. The collected data from all stakeholders will then analyzed and further evaluated so that it will come to the best result of developing the said portal.

Step 4. Collect Data in the Field. The researchers collected and stored multiple sources of evidence format, so that the possibly patterns will revealed.

Step 5. Evaluate and Analyze the Data. The researchers examines raw data from different data gathering tools using many interpretations in order to find the real problem or situation that address to KM practices and academic appeal services. From the multiple data collection methods and analysis techniques it tends to provide opportunities to assess the data in order to strengthen the research findings and conclusions.

Step 6. Prepare the report. After evaluating and analyzing, the researchers provide any form of output by means of translating it in reports. The researchers will use statistical data in presenting output.

B. Survey - Kendall (2008), defined the questionnaires are useful in gathering information from key organization members about attitudes, beliefs, behaviors and characteristics. In the study giving questionnaires is the essential idea on collecting information from the Appeal Committee and since the interviewing is targeting only the few or small number of participants the issues cannot be generalized.

\subsection{Research Instruments}

The researchers used convenience sampling. Convenience sampling method relies on population members who are conveniently available to participate in the study. This method chooses by the researchers because of convenience accessibility and proximity. (Methodology, 2015). Survey (Questionnaires). Kendall (2008), defined the questionnaires are useful in gathering information from key organization members about attitudes, beliefs, behaviors and characteristics. 
The respondents of the develop KM Portal have a total of 54 respondents in evaluating the software. In addition the researchers designed the survey questionnaires for validating and testing the efficiency of the developed KM Portal using software requirement evaluation tool of ISO 9126. ISO 91261 , it measures the standard software quality assurance and software process involvement of the develop system. Below are the 6 main quality characteristics, and these are:
1. Functionality
2. Reliability
3. Usability
4. Efficiency
5. Maintainability
6. Portability

Questions are designed as closed question type's where all the options are listed and are mutually exclusive by using the likert's scale, each respondent is asked to rate each item on some response scale as shown on Figure 5.

Figure 5 - Lickert's Scale Used in Survey

\begin{tabular}{|c|c|}
\hline Numerical Rating & Equivalent \\
\hline 5 & Strongly Agree \\
\hline 4 & Agree \\
\hline 3 & Neutral \\
\hline 2 & Disagree \\
\hline 1 & Strongly Disagree \\
\hline
\end{tabular}

\subsection{Ranking}

It will be used by the researchers to assign the order of significance of the variable to another. The researchers will rank the responses regarding the response after evaluating the KM Portal. Each criterion set in the evaluation instruments has a preset scale of 1 to 5 , where 5 is given to indicate strongly agree and 1 is given to indicate strongly disagree. The data gathered by the researchers was collated and computed to determine the mean and standard deviation and for interpretation of results. Table 1 is used for rating scale to interpret the survey.

Table 1 - Rating Scale

\begin{tabular}{|c|c|}
\hline Numerical Scale & Interpretation \\
\hline $4.51-5.00$ & Strongly Agree \\
\hline $3.51-4.50$ & Agree \\
\hline $2.51-3.50$ & Neutral \\
\hline $1.51-2.50$ & Disagree \\
\hline $1.00-1.50$ & Strongly Disagree \\
\hline
\end{tabular}

\section{METHOD USED IN DEVELOPING THE SYSTEM}

Methodology is one of the most important steps towards software development where it comprises to the researchers' strategic planning towards the life cycle of the system being developed. This is a step-by-step discussion of the methodology adaptation. The researchers used prototyping as software methodology because it provides effective approaches in the development that can perform in an existing simulation before committing to a complete rework effort. Pressman,(2011), stated that Prototyping paradigm begins with communication. The prototype is then deployed and evaluated by stakeholders, who provide feedback that is used to further refine requirements. It also defines the overall objectives of the software, identify requirements, and outline areas where further definition is mandatory.

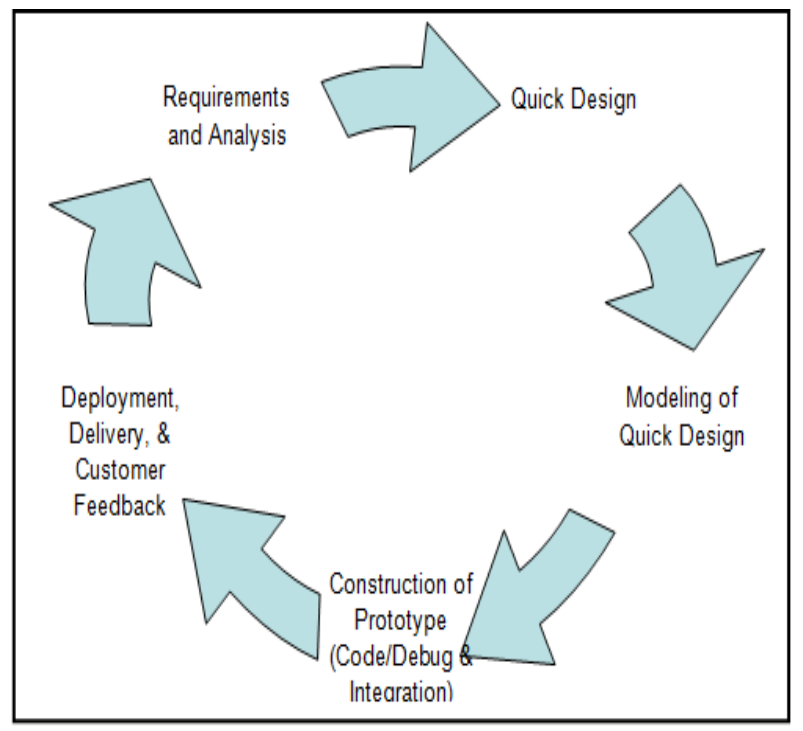

Figure 6 - Prototyping Paradigm - Pressman R.S.(2011)

Figure 6 shows the prototyping model as system methodology in system development. It comprises of phases such as requirements and analysis, quick plan, modeling of quick design, construction of prototype, and deployment delivery \& feedback. Consequently, the researchers use this as an effective paradigm because it address to the development of actual system that relies on the needs of the student's appeal domain.

Requirements and Analysis Phase. This phase is concerned about identifying problems, opportunities, objectives and requirements in order to develop the KM portal. In conceptualization the researchers gathered data by reading and investigating the related literatures, conduct interviews, internet searching, reading books and journal.

Quick Design. The researchers used appropriate design for the system to be more organized and presentable. It includes preliminary design or quick design for the system and includes only the important aspects of the system which give an idea of the system to the user. The researchers designed the preliminary design of a system by creating flowchart.

Modeling of Quick Design. After designing, the preliminary design needs to modify from the suggestions of the users. It is called as rough design of the required system. The researchers designed a rough design of a system by creating dashboard to each important stakeholder who processed the appeal. See the sample screen shot on Figure 7. The dashboard design is for registrar, student, head of appeal, head of department, course coordinator and head of section. 


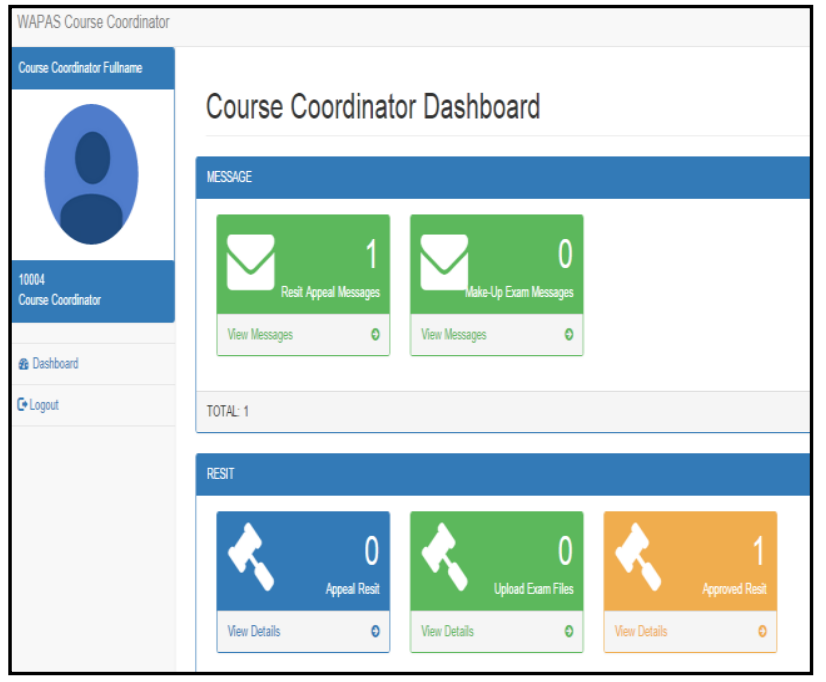

Figure 7 - Modeling Quick Design- Dashboard

Construction of Prototype. In this phase, after the user evaluated the rough prototype, the researchers refined and added some features according to the user requirements. The researchers used the PHP as the programming language and MVC - Model View Controller for the framework design of the system. MVC is the name of methodology or design pattern for connecting the user interface to underlying models. The main objective of this framework is for easily re-use the code and a pattern that allows some functions to call in the user interface.

Deployment Delivery \& Feedback. The final output is thoroughly evaluated and tested followed by routine maintenance to prevent failures and downtime. The researchers used the integration testing because all modules have been tested. The researchers started testing on the registrar account, by uploading the student information, transcript information and curriculum file. After uploading, the researchers used the sample student data entering for the student account. Appeal Head account is used to approve the student appeal as well as the Head of the Department. The Course Coordinator Account is used to enter the schedule and the final grade, and lastly the Head of Section account is used for the final approval of submitted appeal deliverables. Please see the figure 8 for Course Coordinator Dashboard.

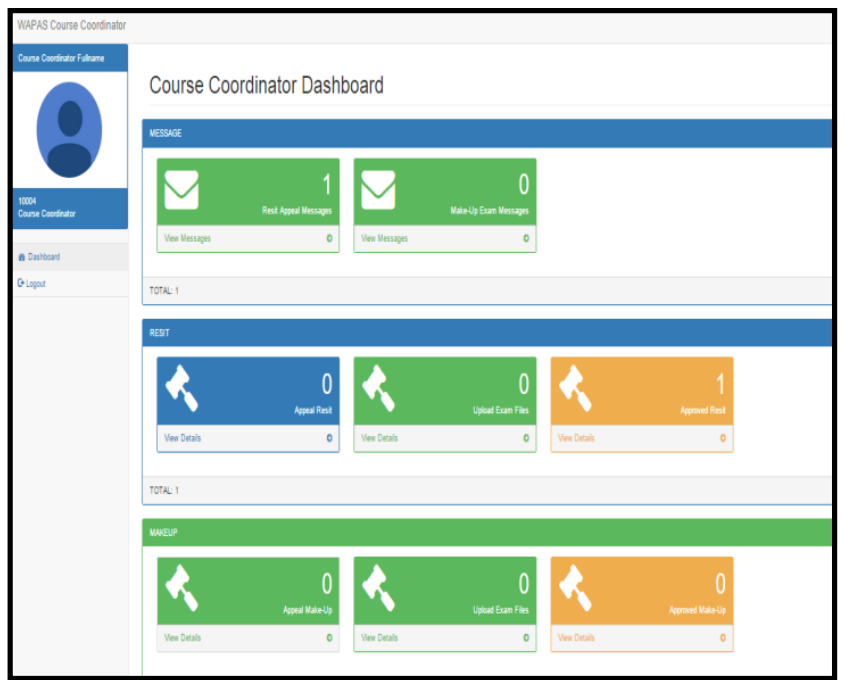

Figure 8 - Course Coordinator Dashboards

\section{SUMMARY OF FINDINGS}

It presents the results from data gathering done by the researchers. It provides analysis and interpretation of each result that will give meaning to the study and will clarify the results. The data gathered were based on the results of the evaluation instruments. Specifically, the study answers the following questions:

1. What is the KM Model is used in proposed KM Portal? Even though, a lot of KM Model can be applied to the study, but the researchers chooses the KM Model by Botha, because the KM activities are overlapped and connected to one another showing KM activities such as: knowledge discovery, knowledge capture, knowledge sharing and knowledge application. It illustrates peopleoriented and technology approach that is very essential in developing the system student's appeal domain.

2. How do the respondents evaluate the proposed KM Portal in terms of Functionality, Reliability, Usability, Efficiency, Maintainability and Portability?

The result assessment of the software development has an interpretation of "Strongly agree" with a weighted mean of 4.56 on the following indicators: functionality, usability, efficiency and maintainability. In addition, reliability and portability with a weighted mean of 4.66 is having a description of "Agree." Below are the summaries of results in terms of:

Functionality (Suitability): The average weighted mean on the respondents is 4.57 with an interpretation of "Strongly Agree".

Functionality (Accurateness): Responses got a total of weighted mean as 4.59. The 3 items got the same interpretation as "Strongly Agree". The average weighted mean on the respondents is 4.57 with an interpretation of "Strongly Agree".

Functionality (Compliance): The average weighted mean on the respondents is 4.57 with an interpretation of "Strongly Agree".

Functionality (Security): The average weighted mean on the respondents is 4.53 with an interpretation of "Strongly Agree".

Reliability (Maturity): The average weighted mean on the respondents is 4.52 with an interpretation of "Strongly Agree".

Reliability (Fault Tolerance): The average weighted mean on the respondents is 4.47 with an interpretation of "Agree".

Reliability (Recoverability): The average weighted mean on the respondents is 4.47 with an interpretation of "Agree".

Usability (Understandability): The average weighted mean on the respondents is 4.60 with an interpretation of "Strongly Agree".

Usability (Learnability): The average weighted mean on the respondents is 4.57 with an interpretation of "Strongly Agree".

Usability (Operability): The average weighted mean on the respondents is 4.53 with an interpretation of "Strongly Agree". 
Efficiency (Time Behavior): The average weighted mean on the respondents is 4.53 with an interpretation of "Strongly Agree".

Efficiency (Resource Behavior): The average weighted mean on the respondents is 4.50 with an interpretation of "Agree".

Maintainability (Analyzability): The average weighted mean on the respondents is 4.53 with an interpretation of "Strongly Agree".

Maintainability (Changeability): The average weighted mean on the respondents is 4.55 with an interpretation of "Strongly Agree".

Maintainability (Stability): The average weighted mean on the respondents is 4.50 with an interpretation of "Agree".

Maintainability (Testability): The average weighted means on the respondents is 4.52 with an interpretation of "Strongly Agree".

Portability (Adaptability): The average weighted means on the respondents in the KM Portal is 4.48 with an interpretation of "Agree".

Portability (Instability): The average weighted means on the respondents is 4.49 with an interpretation of "Agree".

Portability (Conformance): The average weighted means on the respondents is 4.45 with an interpretation of "Agree".

3. What software methodology model used in the development KM Portal?

The researchers used prototyping paradigm as software methodology in the development of the KM portal. They produced a prototype of the portal for pilot testing and the suggestions from the end users were considered to come up with a revised system.

\section{CONCLUSIONS}

The researchers drawn the following conclusions based on the foregoing summary of findings. Hence, based on the perception of the respondents from the given evaluation assessment, the developed software provides the good impression of "strongly agree" to the following indicators: functionality, usability, efficiency and maintainability. Moreover, the study also reveals that the implementation of KM portal to student's appeal committee shows the strongly agree in terms of acceptance amongst stakeholder in improving current manual process, fasten the appeal transaction, providing good decision-making and avoid the favorable response of higher authority amongst students and faculty staff.

\section{REFERENCES}

[1] Ahmed Bahgat El Seddawy, T. S. (2012). Enhanced kmean algorithm to improve decision support system under uncertain situations. International Journal of Modern Engineering Research(IJMER), 4094-4101.

[2] Akila, C. J. (2012). Enhanced bonding based web page information retrieval using clustering algorithm. Ijreas

[3] Barnes, S. (2002). Knowledge Management Systems, Theory and Practice. London: Thomson Learning.

[4] Botha A, Kourie D, \& Snyman R, (2008), Coping with Continuous Change in the Business Environment, Knowledge Management and Knowledge Management Technology, Chandice Publishing Ltd.
[5] Burkhard \& Meier.,(2004). Visualization (computer graphics). Available: http://en.wikipedia.org/wiki/Visualization_(computer_gr aphics)\#Knowledge visualization. [Accessed: 6 November 2014]

[6] Chatterjee, D., Grewal, R., \& Sambamurthy, V. (2002). Shaping up for E-Commerce: Institutional Enablers of the Organizational Assimilation of Web Technologies. MIS Quarterly, 26(2), 65-89

[7] Chun-Wei sai, K.-W. H.-C.-S. (2009). A fast tree-based search algorithm for cluster search engine. International Conference On Systems, Man, And Cybernatics, 8.

[8] Dong, Y. L. (2013). Relationships between student satisfaction and assessment grades in a first-year engineering unit. otl.curtin.edu.au .

[9] Frank, U. (2002). A Multilayer Architecture for Knowledge Management Systems. In Barnes, S. (ed), Knowledge Management Systems: Theory and Practice. Thomsen Learning

[10] Firestone, JM., (2002).Knowledge Management and Quality Management. Available: http://www.dkms.com/papers/kmandqmrev1ppt.pdf. [Accessed: 19 December 2014]

[11] Frost, A. (2013). KM Tool. Retrieved December 22, 2014, from KMT - An Educational KM Site: http://www.knowledge-managementtools.net/knowledge-management-tools.html.

[12] Gamble, P.R., \& Blackwell, J. (2001), Knowledge Management: A State of the Art Guide, Kogan Page Ltd.

[13] Ghini, C. (2012). Information Systems Development Methodology (ISDM). Retrieved June 22, 2015, from myfloridacfo: http://www.myfloridacfo.com/division/dis/isdm/

[14] Ginsburg, M., \& Kambil, A.(2002). Web-based knowledge management support for document collections. In Barnes, S.(Ed.),Knowledge management systems, theory and practice.(pp128-129). London: Thomson Learning.

[15] Grimm.,et.al.(2007).Knowledge Representation and Ontologies Logic, Ontologies and Semantic Web Languages. Available: http://knoesis.wright.edu/pascal/resources/publications/kr -onto-07.pdf [accessed: 19 December 2014]

[16] Hamid Parvin, B. M.-B. (2015). A clustering ensemble framwork based on selection of fuzzy weighted clusters in a locally adaptive clustering algorithm. Journal Pattern Analysis And Applications , 87-112.

[17] Hecht, M., Maier, R., Seeber, I., and Waldhart, G. (2011), "Fostering adoption, acceptance, and assimilation in knowledge management system design", in: Lindstaedt, S., Granitzer, M.: i-KNOW '11 - Proceedings of the 11th International Conference on Knowledge Management and Knowledge Technologies. Graz, Austria - September 07-09, New York: ACM Digital Library, ISBN 978-1-4503-0732-1, pp. 1 - 8.

[18] Irma Becerra-Fernandez, A. (2004). Knowledge Management Challenges, Solutions and Technologies. New Jersey: Upper Saddle River. 
[19] Kendall KE, K. J. (2008). Systems analysis and design (7th ed.). Singapore: Pearson Education South Asia Pte Ltd.

[20] Krishnamurthy, R. (2012). Survey of data mining techniques on crime data analysis. Intenational Journal of Data Mining Techniques and Application .

[21] Liebowitz, J. (1999). Information Technology Management: A Knowledge Repository, CRC Press LLC, 1999

[22] Liebowitz, J. (2009). Knowledge Retention: Strategies and Solutions, CRC Press, LLC

[23] Liebowitz, J. (2011) Knowledge retention: What practitioners need to know, retrieved October 2012 from http://www.kmworld.com/Articles/ReadArticle.aspx?Art icleID=73363

[24] Methodology, R. (2015). Convenience sampling. Retrieved July 28, 2015, from Research Methodology: http://research-methodology.net/sampling/conveniencesampling/

[25] Meso, P. and Smith, R. (2000). "A Resources-based View of organizational knowledge Management
Systems", Journal of Knowledge Management, Vol. 4 No. 3, pp. 224-234.

[26] Pressman, R.S. (2011). Software engineering: A Practitioner's Approach.US: Mc-Graw Hill.

[27] Robertson, J. (2003). Where is the knowledge in a CMS? Step Two Designs. Retrieved on February 2011 from http://www.steptwo.com.au/papers/kmc_wherek/index.ht $\mathrm{ml}$

[28] Rusli Abdullah, M. H. (2005). A Framework For Knowledge Management System Implementation In Collaborative Environment For Higher Learning Institution. Journal of Knowledge Management Practice .

[29] Rogers, E. (1995). Diffusion of Innovations (4th ed., p. 519). Free Press.

[30] Rouse, Margareth.,2006. Data Warehouse or Information Warehouse. Available: http://searchsqlserver.techtarget.com/definition/datawarehouse [accessed: 19 December 2014

[31] Yin, R. (2008). Case study research: design and methods. Thousand Oaks, Calif.: Sage Publishing. 